\title{
Are we addressing relevant determinants of smoking cessation?
}

\author{
To the Editor:
}

The identification of factors that may predict success in smoking cessation efforts is highly desirable as this could help to match smokers with a strategy more likely to help them quit, as well as helping to optimise healthcare resources and refine state-funded tobacco policies. Although several factors have been extensively investigated, both in aided and unaided smoking cessation, no consistent determinants of smoking cessation have been identified [1].

The recent prediction analysis by VAN EERD et al. [2] based on a series of classic candidate predictors of abstinence, from a randomised controlled trial of chronic obstructive pulmonary disease (COPD) smokers, is no exception. That COPD patients with a high level of education (adjusted $\mathrm{OR}=3.23$ ), more favourable general health perception (adjusted $\mathrm{OR}=1.03$ ) and living without a partner (adjusted $\mathrm{OR}=3.89$ ) were more likely to quit smoking is probably due to a chance finding given the small sample size. Clearly, living as a single person or being a widower/widow cannot be a credible predictor of smoking cessation.

Candidate predictors of smoking cessation are generally elected based on theory and existing evidence. However, these paradigmatic factors may not be the relevant ones. It is unfortunate that little emphasis is placed on important dynamic factors that predict relapse. Smoking cessation is a process and relapse is an ordinary component of this process. Therefore, predictor variables commonly recorded at baseline may not be very representative of the dynamic psychological and physical changes occurring in the smoker trying to quit. For instance, withdrawal symptoms, an established cause of relapse, vary in their intensity and duration during abstinence [3]. Individuals undergoing nicotine withdrawal experience both affective and somatic symptoms beginning between 4 and $24 \mathrm{~h}$ after ceasing intake. The syndrome is most severe in the first week but it can persist for longer periods of time. During this time, relapse is incentivized by the ability of nicotine to alleviate or abolish withdrawal symptoms [4]. As such, these individuals are at the highest risk of relapse. Careful monitoring of withdrawal symptoms by validated questionnaires may identify smokers experiencing unremitting symptoms [5]. Other important dynamic factors that predict relapse include self-efficacy and outcome expectancies of quitting after the start of the quit attempt [6].

During cigarette withdrawal syndrome, negative affect and urge to smoke appear to be most robustly altered by abstinence and tend to predict relapse more consistently. Nicotine abstinence also reduces positive affect and this increases cigarette relapse risk. Hence, diminished positive affect is also a possible withdrawal symptom. Overall, changes in affect and urge may be among the most functionally significant symptoms that arise during tobacco abstinence [7].

Moreover, smoking is much more than the addicting effect of nicotine. The ritualistic component of smoking can play an important part in tobacco addiction, as, while the smoker may stop smoking, the need for the ritual still exists and this could be an important cause of relapse [8, 9]. Specific characterisation of behavioural sub-phenotypes using the Glover-Nilsson Smoking Behavioural Questionnaire (GN-SBQ) can be exploited to predict successful smoking cessation [10]. Smokers who were identified by GN-SBQ as being heavily dependent on the behavioural pattern of smoking had a quit rate of $66.7 \%$ when using nicotine-free inhalers, compared with $28.3 \%$ of the reference group. Future prediction analysis should consider incorporation of these important dynamic factors.

@ERSpublications

Predictors recorded at baseline may not be representative of the dynamic psychophysical changes in quitting http://ow.ly/2pk830fFx8x

Cite this article as: Caponnetto P, Polosa R. Are we addressing relevant determinants of smoking cessation? Eur Respir J 2017; 50: 1701615 [https://doi.org/10.1183/13993003.01615-2017]. 
Pasquale Caponnetto and Riccardo Polosa

Smoking Prevention/Cessation Center (CPCT), Institute of Internal Medicine, Azienda Ospedaliero-Universitaria "Policlinico-Vittorio Emanuele", University of Catania, Catania, Italy.

Correspondence: P. Caponnetto, AOU Policlinico-V. Emanuele, Via S. Sofia 78, 95123 Catania, Italy. E-mail: polosa@ unict.it

Received: Aug 082017 | Accepted: Aug 202017

Conflict of interest: None declared.

\section{References}

1 Caponnetto P, Polosa R. Common predictors of smoking cessation in clinical practice. Respir Med 2008; 102 $1182-1192$.

2 van Eerd EAM, van Schayck OCP, Wesseling G, et al. Predictors of long-term smoking cessation in patients with COPD: results from a randomised controlled trial. Eur Respir J 2017; 49: 1700561.

3 Hughes, J. Effects of abstinence from tobacco: valid symptoms and time course. Nicotine Tob Res 2007; 9: 315-327.

4 McLaughlin I, Dani JA, De Biasi M. Nicotine withdrawal. Curr Top Behav Neurosci 2015; 24: 99-123.

5 West R, Ussher M, Evans M, et al. Assessing DSM-IV nicotine withdrawal symptoms: a comparison and evaluation of five different scales. Psychopharmacology (Berl) 2006; 184: 619-627.

6 Gwaltney CJ, Shiffman S, Balabanis MH, et al. Dynamic self-efficacy and outcome expectancies: prediction of smoking lapse and relapse. J Abnorm Psychol 2005; 114: 661-675.

7 Aguirre C, Madrid J, Leventhal AM. Tobacco withdrawal symptoms mediate motivation to reinstate. Smoking during abstinence. J Abnorm Psychol 2015; 124: 623-634.

8 Laurier E, McKie L, Goodwin N. Daily and life course contexts of smoking. Sociol Health Illn 2000; 22: 289-309.

9 Jarvis MJ. ABC of smoking cessation. Why people smoke. BMJ 2004; 328: 277-279.

10 Caponnetto P, Cibella F, Mancuso S, et al. Effect of a nicotine-free inhalator as part of a smoking-cessation programme. Eur Respir J 2011; 38: 1005-1011. 